See Article page 1885.

\section{Commentary: Sponsoring scholarship: Mountains moved by the American Association for Thoracic Surgery}

\author{
Bryan M. Burt, MD, FACS
}

Funding from the National Institutes of Health (NIH) is a pinnacle of scholarship in medicine and in science. NIH grant applications undergo rigorous peer-review and are awarded to only top-percentile submissions that are projected to have a high impact on advancing human health. Whereas clinicians are uniquely positioned to recognize and investigate high-impact opportunities, only $1.5 \%$ of researchers in the United States are physician-scientists. ${ }^{1}$ Surgeons are particularly under-represented among NIHfunded physicians, yet surgeon-scientists are highly productive and the output from their grants is highly influential. ${ }^{2}$ Securing a R01-equivalent award from the NIH is generally considered necessary to sustain a successful research program, and assembly of an exceptional application realistically requires years of preparation and a deep understanding of the grant-review process. Victory is achieved by few applicants, who all contend with unforgiving NIH paylines, but surgeons are faced with a common challenge: the same clinical practices that offer opportunity to innovate require a substantial time commitment that competes with the effort necessary to establish a rigorous parallel research program. Reaching funding at the individual surgeon level is an formidable task, and addressing the

\footnotetext{
From the Michael E. DeBakey Department of Surgery, Division of General Thoracic Surgery, Baylor College of Medicine, Houston, Tex.

Dr Burt is a member of the American Association for Thoracic Surgery (AATS), a member of the Scientific Affairs and Government Relations (SAGR) Committee of the AATS, and receives research funding from the National Institutes of Health (NIH).

The Journal policy requires editors and reviewers to disclose conflicts of interest and to decline handling or reviewing manuscripts for which they may have a conflict of interest. The editors and reviewers of this article have no conflicts of interest.

Received for publication Oct 25, 2021; revisions received Oct 25, 2021; accepted for publication Oct 26, 2021; available ahead of print Oct 29, 2021.

Address for reprints: Bryan M. Burt, MD, FACS, The Michael E. DeBakey Department of Surgery, Baylor College of Medicine, One Baylor Plaza, MS BCM 390,

Houston, TX 77030 (E-mail: bryan.burt@bcm.edu).

J Thorac Cardiovasc Surg 2023;165:1899-900

$0022-5223 / \$ 36.00$

Copyright (C) 2021 by The American Association for Thoracic Surgery

https://doi.org/10.1016/j.jtcvs.2021.10.040
}

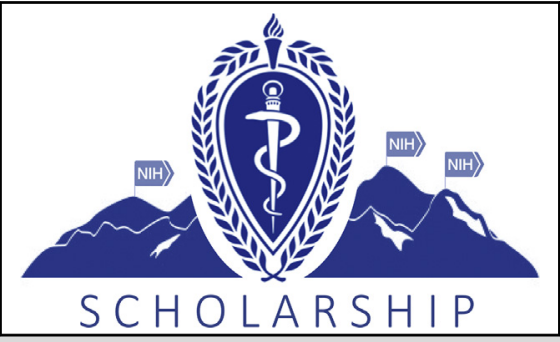

More surgeons are reaching the summit of NIH funding with the sponsorship of the AATS.

\section{CENTRAL MESSAGE \\ Focused efforts by the American Association for Thoracic Surgery have increased $\mathrm{NIH}$ funding for its surgeons and represent the grandest form of sponsorship.}

deficit in the surgeon-scientist workforce would seem to require the movement of mountains. ${ }^{3}$

The American Association for Thoracic Surgery (AATS) was founded in 1917 by the earliest pioneers in cardiothoracic surgery. Through scholarship, innovation, and leadership, the AATS had demonstrated unwavering commitment to advancing our field and is addressing, head-on, the deficit in the surgeon-scientist workforce. Through a portfolio of efforts, the AATS promotes academic development of cardiothoracic surgeons. Grant writing workshops, clinical trials courses, and innovation summits are held to develop the research careers of surgeons. Through the AATS Foundation, the AATS directly promotes research activity by funding a long-standing series of pilot grants to cardiothoracic surgeon-scientists aspiring to obtain NIH funding. Importantly, on a much larger scale, the AATS has established a Scientific Affairs and Government Relations committee that identifies and interacts with funding agencies and that serves as a resource for surgeons to identify available funding opportunities and to gain the essential understanding of funding mechanisms and processes.

In their manuscript, Mehaffey and colleagues ${ }^{4}$ investigated the impact that these AATS activities had on increasing NIH funding to cardiothoracic surgeons. The investigators constructed a novel database of cardiothoracic surgeons in the United States and cross-referenced this database to NIH grant records. Their findings were provocative and uplifting. Over the last three-and-one-half decades, 
cardiothoracic surgeons have received more than $\$ 1.5$ billion in NIH funding. Direct correlations were observed between Scientific Affairs and Government Relations activity and an increasing number of funded cardiothoracic surgeons as well as to an increasing number of research grants awarded to cardiothoracic surgeons. Although these data are correlative and not causal, the investigators used rigorous statistics to infer a compelling likelihood of causality. Perhaps the strongest support for the authors hypothesis that AATS activities have helped to increase NIH grants awarded to cardiothoracic surgeons was the strong association with the incidence of new research grants to the individuals surgeons who participated in an AATS academic development program. By investing in their surgeons' career success, advocating for their surgeons, and promoting scholarship among their surgeons, the AATS models sponsorship on the grandest level. Although this level of sponsorship has been present in the name of the American Association for (not "of") Thoracic Surgery since its inception more than 100 years ago, it is now scientifically proven by Mehaffey and colleagues.

\section{References}

1. National Institutes of Health. Size and Composition of the Physician-Scientist Workforce in 2012. Accessed September 25, 2021. Physician-Scientist Workforce (PSW) Report 2014: Executive Summary. https://report.nih.gov/workforce/psw/ size_composition.aspx

2. Narahari AK, Mehaffey JH, Hawkins RB, Charles EJ, Baderdinni PK, Chandrabhatla AS, et al. Surgeon scientists are disproportionately affected by declining NIH funding rates. J Am Coll Surg. 2018;226:474-81.

3. Salata RA, Geraci MW, Rockey DC, Blanchard M, Brown NJ, Cardinal LJ, et al. U.S. physician-scientist workforce in the 21st century: recommendations to attract and sustain the pipeline. Acad Med. 2018;93:565-73.

4. Mehaffey J, Wang H, Narahari AK, Bajaj SS, Chandrabhatla AS, Krupnick AS, et al. The impact of the American Association for Thoracic Surgery on National Institutes of Health grant funding for cardiothoracic surgeons. J Thorac Cardiovasc Surg. 2023;165:1885-96.e7. 